\title{
Zihinsel Yetersizlik ve Retinitis Pigmentosa Birlikteliğinin Nadir Bir Nedeni: Laurence Moon Bardet Biedl Sendromu
}

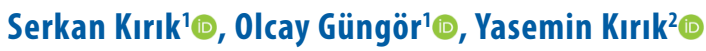

'Sütçü İmam Üniversitesi, Çocuk Nöroloji, Kahramanmaraş, Türkiye ${ }^{2}$ Necip Fazıl Şehir Hastanesi, Enfeksiyon Hastalıkları ve Klinik Mikrobiyoloji, Kahramanmaraş, Türkiye

Serkan Kırık, Dr. Olcay Güngör, Dr. Yasemin Kırık, Dr.
İletişim:

Dr. Serkan Kirik

Sütçü Imam Üniversitesi, Çocuk Nöroloji, Kahramanmaraş, Türkiye

Tel: +905055771480

E-Posta: srknkrk@hotmail.com

Gönderilme Tarihi : 07 Mart 2017

Revizyon Tarihi : 23 Temmuz 2017

Kabul Tarihi ： 24Temmuz 2017
ÖZET

Laurence Moon Bardet Biedl sendromu nadir, otozomal resesif bir hastalıktır. Hastalar obezite, renal anormallikler, görme anormallikleri, hipogonadizm ve zihinsel yetersizlik ile prezente olurlar. Bu olgu sunumunda 11 yaşında algılama güçlüğü ve retinitis pigmentosa ile başvuran ve incelemeler sonucu Laurence Moon Bardet Biedl Sendromu tanısı alan erkek hasta literatür bilgileri doğrultusunda değerlendirilerek sunulmuştur. Zihinsel yetersizlik ve retinitis pigmentosanın nadir nedenlerinden birinin Bardet Biedl sendromu olabileceğine dikkat çekilmiştir.

Anahtar sözcükler: Bardet Biedl sendromu, zihinsel yetersizlik, retinitis pigmentosa

\section{A RARE CAUSE OF MENTAL RETARDATION AND RETINITIS PIGMENTOSA: LAURENCE MOON BARDET BIEDL SYNDROME}

\section{ABSTRACT}

Laurence Moon Bardet Biedl syndrome is a rare, autosomal recessive disorder. Patients present with obesity, renal abnormalities, visual abnormalities, hypogonadism and mental retardation. In this case report, a 11-year-old male patient presented with absence of perception and retinitis pigmentosa who was diagnosed with Laurence Moon Bardet Biedl Syndrome. It was noted that one of the rare causes of mental retardation and retinitis pigmentosa is Bardet Biedl syndrome.

Keywords: Bardet Biedl syndrome, mental retardation, retinitis pigmentosa

aurence Moon Bardet Biedl sendromu (LMBS) nadir görülen, otozomal resesif kalıtılan multisistemik genetik bir hastalıktır (1). Trunkal obezite, renal anormallikler, retinal anormallikler, hipogonadizm ve mental retardasyon ile presente olurlar. Bu hastalarda bu temel klinik özelliklere ek olarak nörolojik komplikasyonlar, kardiyak anomaliler, diabetes mellitus, hepatik fibrozis, multipl nevus gibi bazı anomaliler de sendromla birlikte görülebilmektedir $(2,3)$.

Koni-rod distrofi, retinal disfonksiyonun bir şeklidir. Retina, görüntülerin gözün arkasında odaklandığı ş̧ı̆a duyarlı zardan oluşur. Koni-rodların (fotoreseptörler) distrofisi sonucu görme kaybı gelişir (3). Zihinsel yetersizlik ve IQ puanlarındaki düşüklük çoğunlukla görme sorunlarının sonucu olmakla beraber, hastaların yaklaşık yarısında ciddi zihinsel yetersizlik eşlik edebilir. En sık görülen parmak anomalisi polidaktili olmakla birlikte brakidaktili ve sindaktili de olgulara eşlik edebilir $(1,3)$. 
Bu vaka raporunda zihinsel yetersizlik ve obezite varlığında retinitis pigmentosanın nadir bir nedeni olan LMBS'yu hatırlatmak istedik.

\section{Olgu sunumu}

On bir yaşında erkek hasta çocuk nöroloji polikliniğine okul başarısında yaşıtlarına göre gerilik ve algılama güçlüğü ile başvurdu. Özgeçmişinde, miyadında normal vajinal yolla 3100 gr ağırlığında doğmuş ve 4 aylıkken sol elde polidaktili nedeniyle opere edilmişti. Hastanın 8 aylıkken ve 13 aylıkken febril nöbet öyküsü vardı. Kilo alımı 1 yaşından sonra belirginleşmişti. Geceleri elindekileri düşürme ve ayağının sık olarak takılmasından şikayet ediyordu. Soy geçmişinde anne ve baba 1. derece akrabaydı (amca çocukları).

Fizik muayenede vücut ağırlığı 61 kg (>97 persentil), boyu $140 \mathrm{~cm}$ (25 persentil), vücut kitle indeksi 31,1'di (>95 persentil). Hastada polidaktiliye ait skar izi ve brakidaktili (Şekil 1), trunkal obezite (Şekil 2), derin yerleşimli gözler ve bitemporal darlık mevcuttu (Şekil 3). Hastanın hipogonadizmi (mikropenis ve testis volümünde düşüklük) mevcuttu.

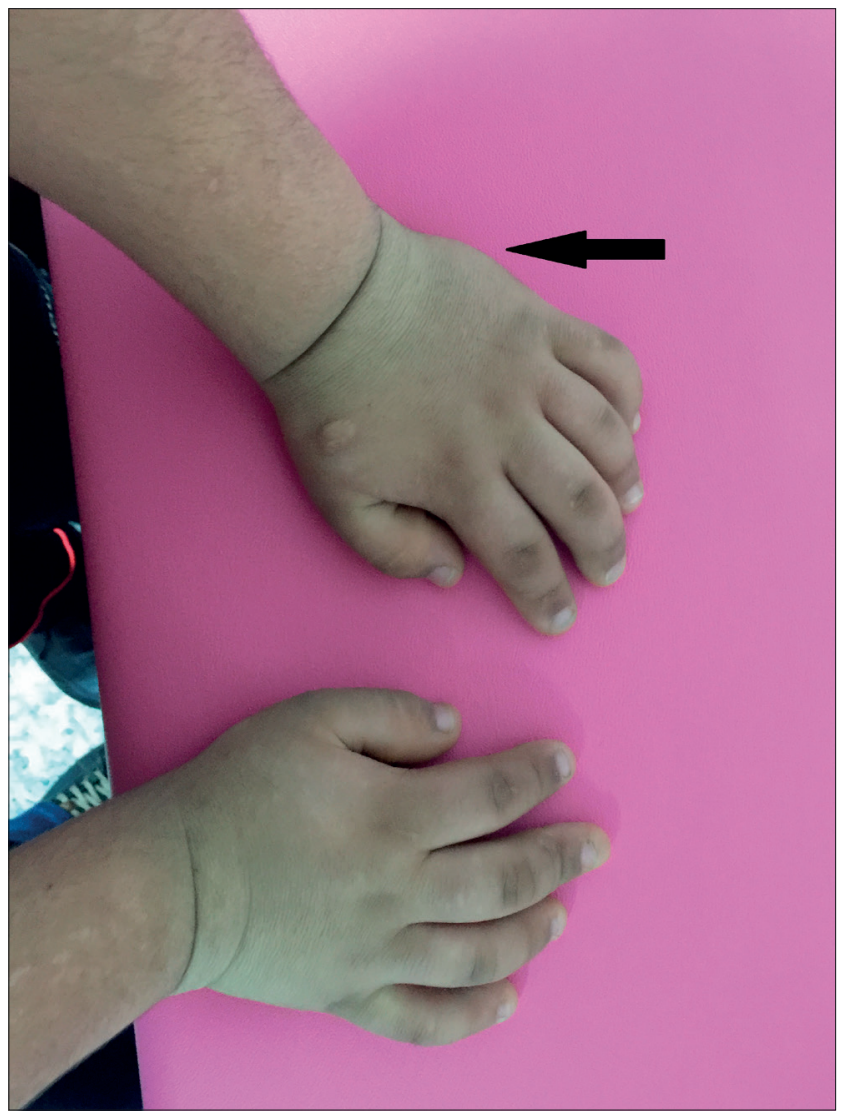

Şekil 1. Siyah ok ile gösterilen bölgede 6. parmağa ait operasyon skarı ve brakidaktilinin görünümü.

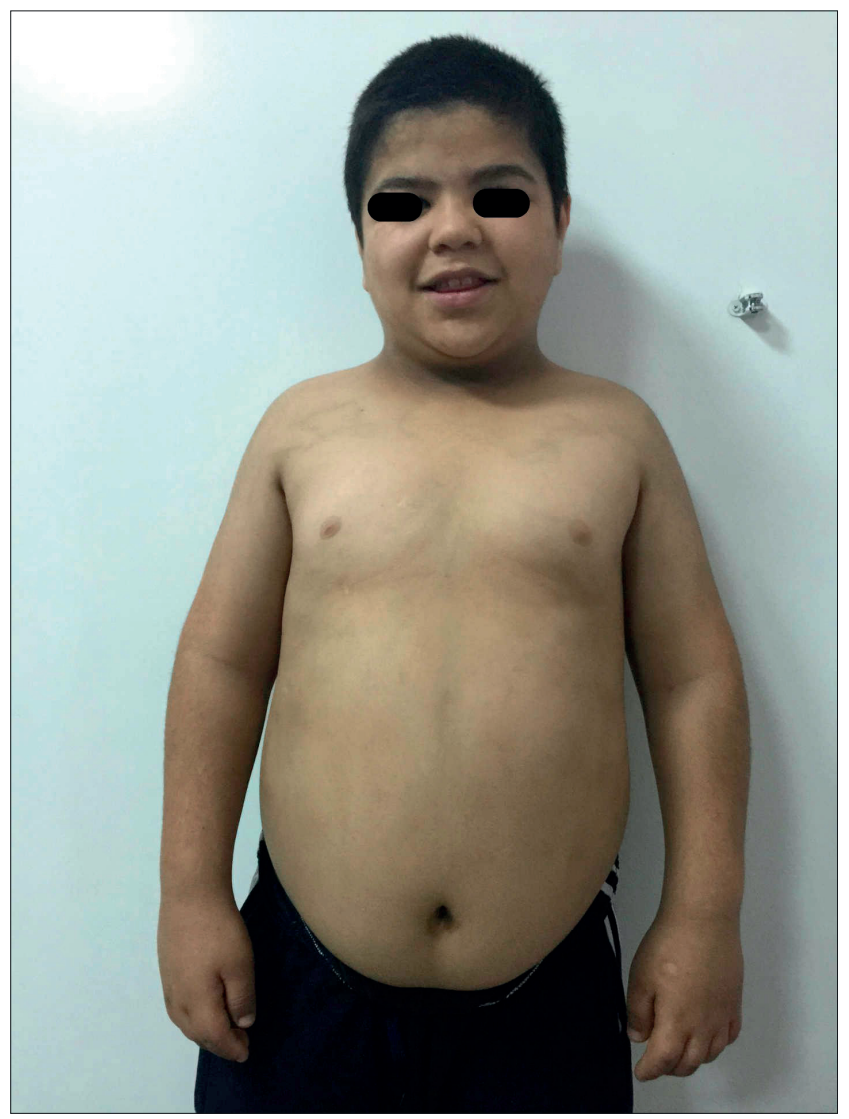

Şekil 2. Hastada trunkal obezitenin genel görünümü.

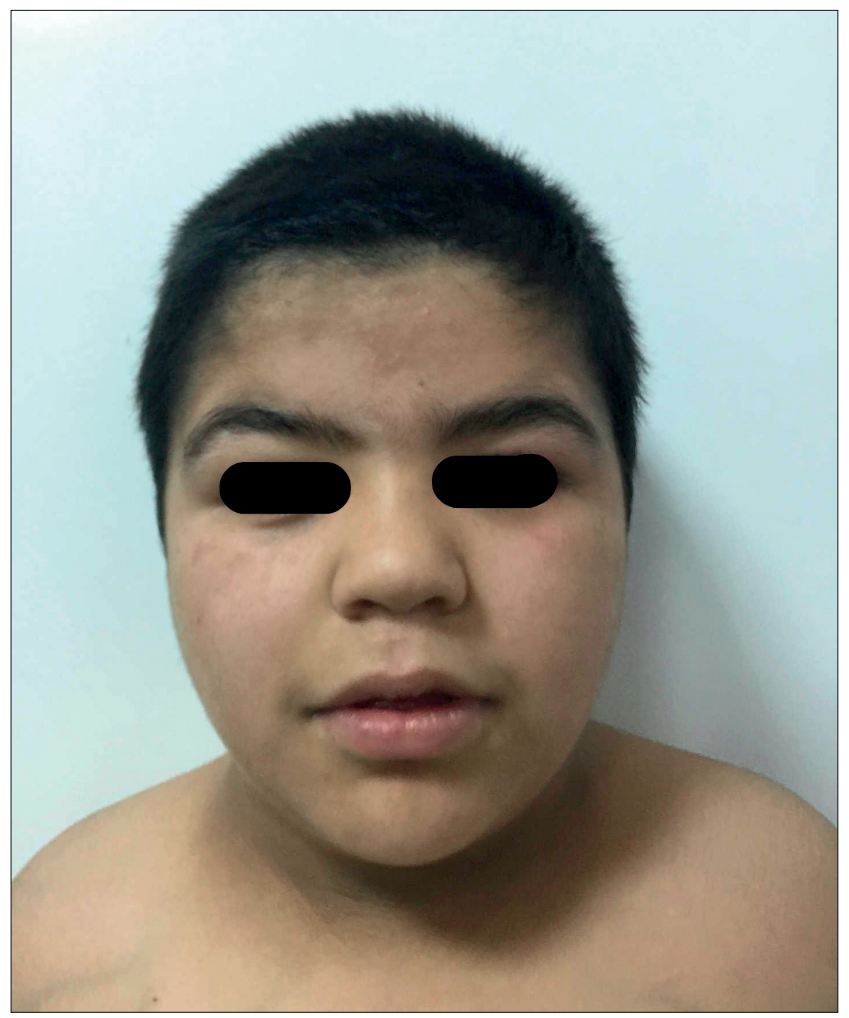

Şekil 3. Hastada derin yerleşimli gözlerin ve bitemporal darlı̆ın görünümü. 
Hasta LMBS ön tanısıyla konsülte edildi. Hastada retinitis pigmentosa saptandı. Hastanın algılaması zayıftı ve IQ testi puanı 50 (orta derece mental retarde) olarak saptandı.

Laboratuar testlerinde, total testesteron $2,4 \mathrm{ng} / \mathrm{dL}$, serbest testesteron $0,42 \mathrm{pg} / \mathrm{ml}, \mathrm{FSH} 5,04 \mathrm{mlU} / \mathrm{mL}$, LH 0,77 $\mathrm{mIU} / \mathrm{mL}$ olarak tespit edildi ve pre-pubertal değerlerle uyumlu bulundu. Renal anomaliler açısından bakılan renal ultrasonografisinde (USG) grade 1 hidronefroz saptandı. Çocuk nefroloji kliniği ile konsülte edildi. Çocuk nefroloji kliniğince takip önerildi. Hastada işitme ise normaldi. Hasta, mevcut fizik muayene bulguları ve anamnez ile Laurence Moon Bardet Biedl sendromu tanısı aldı.

\section{Tartışma}

Laurence Moon sendromu (LMS) 1865 yılında Zachariah Laurence ve Robert Moon tarafından; zihinsel yetersizlik, retinopati, hipogonadizm ve spastik parapleji komponentlerini içeren fakat obezite ve polidaktili içermeyen bir durum olarak tanımlanmıştır. Daha sonra 1920'de George Bardet ve Arthur Biedl, parapleji olmaksızın obezite ve postaksiyal polidaktili ek özellikleriyle bu durumu Bardet-Biedl sendromu (BBS) olarak adlandırmıştır $(1,4)$. Erkek/kadın oranı 47/41dir. Kuzey Amerika ve Avrupa'da 1:140000 ile 1:160000 oranında görülürken, daha izole bir toplum olan Faroe Adaları' nda bu oran 1:3700'dür (2).

Zihinsel yetersizlik sendromun esas özelliklerinden biridir ve olguların \%87'sinde görülmektedir. Motor retardasyon göz bulguları belirginleşinceye kadar eşlik etmez. Ciddi zihinsel yetersizlikle beraber ve nadiren psikoz da görülebilir. IQ puanı 80 'in altında olan hasta sayısı bazı çalışmalarda \%44 civarında bildirilmiştir $(4,5)$. Bizim hastamızda da algılama güçlüğü ve okul başarısında gerilik mevcut olup, IQ' su 50'ydi.

Göz bulgularının klasik şekli retinitis pigmentosadır ve olguların büyük kısmında mevcuttur. Görme bozukluğunun ilerlemesi ve derecesi etkilenen kişiler arasında değişiklik gösterir. Çoğu durumda görme, birinci ve ikinci dekad boyunca giderek kötüleşir. Etkilenen kişilerde bazen periferik görme kaybı meydana gelir (5). Çocukluk ya da ergenlik döneminde, etkilenen hastaların çoğunda makula dejenerasyonuyla beraber santral görme bozukluğu gelişir ve ciddi görme bozukluklarına veya total görme kaybına neden olur. Bazı vakalarda retinanın dejenerasyonu, gece körlüğü ve renk ayırt etme kabiliyetinin kaybına neden olarak retinitis pigmentosanın karakteristik seyrini izler (3-5). Morbidite açısından bu durum hastalarda oldukça önemlidir. Bizim hastamızda da retinitis pigmentoza mevcuttu.

Parmak anomalileri olguların çoğunda mevcuttur. Polidaktili genelde 5. parmağın yanında olur ve ayaklarda ellerden daha sık görülür. Ek olarak el parmakları ve ayak parmakları normalden kısa (brakidaktili) olabilir. Diğer parmak anomalileri klinodaktili ve sindaktilidir $(1,4,5)$. Bizim hastamızda sol elde opere edilmiş polidaktiliye ait skar izi ve her iki elde brakidaktili mevcuttu.

Hastalarda diğer bir yaygın durum obezitedir. Obezite tam olarak netliğe kavuşmasa da leptin direnci ve anormal adipogenez ile ilişkilendirilmiştir. Obezite kol ve bacaklara kıyasla göğüs ve abdomende aşırı yağ birikimi nedeniyle trunkaldir. Doğum ağırlığı genelde normal olup bir yaş civarı kilo alımında artış olur $(2,6)$. Bizim hastamızda da trunkal obezite (BMI: 31,1) mevcuttu.

Hipogonadizm erkeklerde gonadlarda azalmış boy ve azalmış fonksiyon ile ilişkili olabilir. Ek anomaliler arasında mikropenis, kriptorşidizm ve pubertede gecikme sayılabilir. Erkek hastalarda testosteron seviyesi düşük bulunur $(5,6)$. Hastamızda LH ve testosteron düzeyi düşüktü. Mikropenisi mevcuttu. Testis volümü düşük olarak saptandı.

Bardet Biedl sendromu olan bazı bireylerde böbreklerin yapısında ve/veya işlevlerinde anormallikler görülebilir. Bu durum potansiyel olarak hidronefroz veya piyelonefrite neden olabilir (7). Ek olarak renal histolojide kronik interstisyel nefrit, mezengial proliferatif glomerülopati ve glomerüler bazal membranda yapısal değişiklikler görülebilir. Bunların sonucu ortaya çıkan kronik böbrek yetmezliği en sık ölüm nedenidir $(2,7)$. Hastamızda da grade 1 hidronefroz mevcuttu.

Sonuç olarak okul başarısında gerilik ile başvuran obez bir hastada, beraberinde retinitis pigmentosa, polidaktili, renal anormallikler ve mikropenis gibi bulgular da eşlik ediyorsa bu hastalarda LMBS düşünülmelidir. Böylelikle uzun vadede ortaya çıkabilecek böbrek yetmezliği gibi durumlara daha erken müdahale şansı doğacaktır. 


\section{Kaynaklar}

1. Green JS, Parfrey PS, Harnett JD, Farid NR, Cramer BC, Johnson G, et al. The cardinal manifestations of Bardet-Biedl syndrome, a form of Laurence-Moon-Biedl syndrome. N Engl J Med. 1989;321: 1002-9. [CrossRef]

2. Castro-Sánchez S, Álvarez-Satta M, Valverde D. Bardet-Biedl syndrome: A rare genetic disease. J Pediatr Genet. 2013;2: 77-83. [CrossRef]

3. Iannello S, Bosco P, Cavaleri A, Camuto M, Milazzo P, Belfiore F: A review of the literature of Bardet-Biedl disease and report of three cases associated with metabolic syndrome and diagnosed after the age of fifty. Obes Rev 2002;3: 123-35.

4. Moore SJ, Green JS, Fan Y, et al., Clinical and genetic epidemiology of Bardet-Biedl syndrome in Newfoundland: a 22-year prospective, population-based, cohort study. Am J Med Genet A. 2005;132:35260. [CrossRef]
5. Priya S, Nampoothiri S, Sen P, Sripriya S. Bardet-Biedl syndrome: Genetics, molecular pathophysiology, and disease management. Indian J Ophthalmol. 2016;64 :620-7. [CrossRef]

6. Bahceci M, Dolek D, Tutuncuoglu P, Gorgel A, Oruk G, Yenen I. A case series of Bardet-Biedl syndrome in a large Turkish family and review of the literature. Eat Weight Disord. 2012;17:66-9.

7. Beales PL, Reid HA, Griffiths MH, Maher ER, Flinter FA, Woolf AS, Renal cancer and malformations in relatives of patients with BardetBiedl syndrome. Nephrol Dial Transplant 2000;15: 1977-85. 